\title{
The Enthalpies of Combustion and Formation of Acetanilide and Urea
}

\author{
Walter H. Johnson \\ Institute for Materials Research, National Bureau of Standards, Washington, D.C. 20234
}

(January 17, 1975)

\begin{abstract}
The enthalpies of combustion of acetanilide and urea have been determined in an oxygen-bomb calorimeter. The following values and their estimated uncertainties were obtained.

\begin{tabular}{l|c|c}
\hline \hline & Acetanilide & Urea \\
\cline { 2 - 3 }$\Delta H c^{\circ}\left(25^{\circ} \mathrm{C}\right)$ & $-4224.88 \pm 0.93 \mathrm{~kJ} / \mathrm{mol}$ & $-631.78 \pm 0.16 \mathrm{~kJ} / \mathrm{mol}$ \\
$\Delta H f^{\circ}\left(25^{\circ} \mathrm{C}\right)$ & $-209.40 \pm 1.00 \mathrm{~kJ} / \mathrm{mol}$ & $-333.39 \pm 0.17 \mathrm{~kJ} / \mathrm{mol}$ \\
\hline
\end{tabular}
\end{abstract}

A comparison with previously reported data is given.

Key words: Combustion; enthalpy; formation; heat; secondary standard; thermochemical standard.

\section{Introduction}

There is need for a standard reference material for use in the combustion calorimetry of nitrogen-containing compounds. These compounds may be divided into two main classes: (1) those containing relatively small amounts of nitrogen which may be burned without an auxiliary material and (2) those containing larger amounts which require an auxiliary material for ignition and complete combustion. Acetanilide, which contains 10.4 wt percent nitrogen, has been proposed as a secondary standard for compounds which do not require any auxiliary material. It is available in high purity, is nonhygroscopic, has a very low vapor pressure, can be pressed into reasonably good pellets, can be ignited with any type of fuse and burns completely without an auxiliary substance. It is available through the Office of Standard Reference Materials (OSRM) as a microanalytical standard for nitrogen compounds.

Urea, which contains 46.6 wt percent nitrogen, has been proposed as a secondary standard for materials containing larger amounts of nitrogen. Like acetanilide, it appears to have the physical characteristics of a good secondary reference standard. It is available as an analytical standard for clinical laboratories through the Office of Standard Reference Materials.

\section{Materials}

Acetanilide

The sample was obtained from the OSRM as SRM 141B. The certificate gave the purity as 99.99 mol percent. It was stored in air at room temperature and was burned as received with no attempts at further purification.

Urea

The sample was obtained from the OSRM as SRM 912. The certificate of analyses gave the purity as 99.7 weight percent with impurities being moisture, 0.18 percent; biuret, 0.07 percent; ash, 0.002 percent, and insoluble matter, 0.002 percent. We believed that the moisture content was significantly less than the certificate value because repeated drying at $100{ }^{\circ} \mathrm{C}$ gave a constant loss of weight, approximately 0.012 percent $/ \mathrm{h}$, which must be attributed to volatilization of the sample. A redetermination of the moisture content of the sample by S. Margolis of this Bureau found $0.02 \mathrm{wt}$ percent. It appears that some loss of moisture occurred after the initial determination. 


\section{Apparatus and Procedure}

The adiabatic rotating-bomb calorimeter, the adiabatic shield-controls and the method of temperature measurement will be described in a forth-coming publication [1]. A partial description is given in a report by Armstrong and Johnson [2].

The calorimeter was calibrated by a series of combustion experiments using benzoic acid, SRM 39i. In each experiment a sample of approximately $0.3 \mathrm{~g}$ was pressed into a pellet, weighed into a platinum crucible and placed in the bomb which contained $0.3 \mathrm{~cm}^{3}$ of water. The bomb was sealed, filled with $30 \mathrm{~atm}$ $(3.040 \mathrm{MPa})$ of oxygen and the oxygen was released slowly; the bomb was refilled to 31.62 atm $(3.204 \mathrm{MPa})$, and transferred to the calorimeter. The temperature of filling was observed, the calorimeter jacket was evacuated, the bomb was heated electrically to $24.98^{\circ} \mathrm{C}$ and the sytem was left overnight with the pumps and the adiabatic temperature controls in operation.

On the following day, calorimeter temperatures were observed at intervals during an initial rating period and the sample was ignited by means of an electrical current through a platinum wire fuse which was in contact with the sample. Approximately 3 min after ignition the bomb was rotated to obtain a homogeneous bomb solution. After about $20 \mathrm{~min}$ thermal equilibrium was established and calorimeter temperatures were observed at intervals during the final rating period. Because of the heating effect of the $5 \mathrm{~mA}$ current through the platinum resistance thermometer, a steady rise in the temperature of the calorimeter (approximately $0.001 \mathrm{~K} / \mathrm{h}$ ) was observed during the rating periods. The temperature rise due to the overall bomb process was obtained by extrapolation of the time-temperature curves to the actual time of ignition.

The bomb was removed from the calorimeter, the gaseous contents were released, the bomb was opened and the bomb solution transferred to a beaker. The solution was boiled to remove traces of carbon dioxide, cooled and titrated with standard alkali using a $\mathrm{pH}$-meter to determine the quantity of nitric acid. In some cases the solution was analyzed for nitrous acid but the quantities observed were completely negligible.

The procedure with acetanilide was the same as that for benzoic acid except that the quantity of water initially placed in the bomb was $3.000 \mathrm{~cm}^{3}$. The procedure for the urea experiments was the same as for acetanilide except that a small pellet of benzoic acid, was added. The pellets of urea were made in a special press which produced a cavity $3.5 \mathrm{~mm}$ in diameter and $1.5 \mathrm{~mm}$ in depth in the top of the pellet. Another press was used to make a pellet of benzoic acid which was $3 \mathrm{~mm}$ in diameter and about $1 \mathrm{~mm}$ thick. The urea pellet was weighed into the crucible, the benzoic acid pellet was dropped into the cavity and total weight was observed. The platinum fuse wire was adjusted so that it was in contact with the benzoic acid pellet.

\section{Results and Calculations}

The unit of energy is the joule; for conversion to the conventional thermochemical calorie, $1 \mathrm{cal}_{\mathrm{th}}=4.184 \mathrm{~J}$.
The certified value for benzoic acid, SRM 39i, under certificate conditions is $26434 \pm 3 \mathrm{~J} / \mathrm{g}$. This reduces to $\Delta U^{\circ} C\left(28^{\circ} \mathrm{C}\right)=-26410.36 \pm 3 \mathrm{~J} / \mathrm{g}$. The following values have been used in the calculations.

\begin{tabular}{l|c|c|c}
\hline \hline & density, $\mathrm{g} \cdot \mathrm{cm}^{-3}$ & $\mathrm{Cp}, \mathrm{J} \cdot \mathrm{g}^{-1} \mathrm{~K}^{-1}$ & $\left(\frac{\partial U}{\partial P}\right)_{t}, \mathrm{~J} \cdot \mathrm{g}^{-1} \cdot \mathrm{atm}^{-1}$ \\
\cline { 2 - 4 } Benzoic acid....... & 1.320 & 1.21 & -0.0126 \\
Acetanilide........ & 1.22 & 1.39 & -0.0069 \\
Urea............... & 1.21 & 1.55 & -0.005 \\
\hline
\end{tabular}

The heat of decomposition of the nitric acid in the bomb solution into nitrogen, oxygen, and water has been taken as $59.7 \mathrm{~kJ} / \mathrm{mol}$. The auxiliary data was taken from Wagman et al., NBS Tech. Note 270-3 [3]. All values are based on the 1971 Table of International Atomic Weights [4]. All calculations were performed by computer. ${ }^{1}$

The results of the benzoic acid calibration experiments are given in table 1 . The headings, in the order in which they appear in the tables, are described as follows:

EEE-Std, the effective energy equivalent of the standard, empty calorimeter at the standard mean temperature of the experiment.

$C_{v-c o n t}(i)$, the heat capacity of the initial bomb contents, including the sample, crucible, water and oxygen;

Corr to tm, a correction to the heat capacity of the initial system for deviation of the actual mean temperature of the experiment from the standard mean temperature;

Corr-parts, a correction for alterations to the system during the series of experiments;

EEE-actual, the effective energy equivalent of the actual system at the actual mean temperature of the experiment;

Temp. rise, the observed increase in temperature of the system following ignition of the sample;

$Q$-total, the total quantity of energy evolved obtained as minus the product of the temperature rise and EEE-actual;

$q$-ign, the electrical energy added to the system to ignite the sample;

$q$-decomp $\mathrm{HNO}_{3}$, the calculated quantity of energy required to decompose any nitric acid, formed in the combustion process, into nitrogen, oxygen, and water;

$q$-WC, the Washburn Correction [5,6] applied to convert all reactants and products to their respective standard states at the actual final temperature;

$q$-corr to std $t_{f}$, a correction applied for deviation of the actual final temperature from the selected standard final temperature;

$Q$-std react, the energy evolved by the reaction with products and reactants in their respective

${ }^{1}$ The computer program used was originally prepared by C. H. Shomate of the Nava Ordinance Test Station, China Lake, California, and later revised by G. T. Armstrong and E. J. Prosen of this Bureau, according to the method of Hubbard, Scott, and Waddington [5]. 
standard states at the selected final temperature obtained as the sum of $Q$-total and $\Sigma q$.

$m_{s}$, the mass of sample

$\Delta U c^{\circ}$, the energy evolved by the standard reaction at the standard final temperature in $J \cdot g^{-1}$.

The results have been taken directly from the computer print-out and have been rounded for convenience; for this reason small differences may result by calculation from the tabulated data.

The results of the values for the effective energy equivalent from the benzoic acid calibration experiments were determined by an iterative procedure from the mass of sample. The standard calorimeter included the empty bomb and all internal platinum parts except the crucible.

The results of the seven experiments on acetanilide are given in table 2 and correspond to the reaction:

$$
\begin{aligned}
\mathrm{C}_{8} \mathrm{H}_{9} \mathrm{ON}(\mathrm{c})+9.75 \mathrm{O}_{2}(\mathrm{~g}) \rightarrow & 8 \mathrm{CO}_{2}(\mathrm{~g}) \\
& +4.5 \mathrm{H}_{2} \mathrm{O}(\mathrm{liq})+0.5 \mathrm{~N}_{2}(\mathrm{~g})
\end{aligned}
$$

$\Delta U c^{\circ}\left(28^{\circ} \mathrm{C}\right)=-31230.00 \mathrm{~J} / \mathrm{g}, \mathrm{sdm}= \pm 1.72 \mathrm{~J} / \mathrm{g}$.

The results of the seven experiments on urea are given in table 3 and correspond to the reaction:

$$
\begin{aligned}
& \mathrm{CH}_{4} \mathrm{ON}_{2}(\mathrm{c})+1.5 \mathrm{O}_{2}(\mathrm{~g}) \rightarrow \mathrm{CO}_{2}(\mathrm{~g})+2 \mathrm{H}_{2} \mathrm{O}(\mathrm{liq})+\mathrm{N}_{2}(\mathrm{~g}) \\
& \Delta U c^{\circ}\left(28^{\circ} \mathrm{C}\right)=-10536.56 \mathrm{~J} / \mathrm{g}, \mathrm{sdm}= \pm 0.30 \mathrm{~J} / \mathrm{g} .
\end{aligned}
$$

The results of this investigation and the values derived from the results are summarized in table 4 . The uncertainties assigned to $\Delta U c^{\circ}$ and $\Delta H c^{\circ}$ were obtained by combining (square root of the sum of squares) $2 \mathrm{sdm}$ (in \%) for the calibration experiments, $2 \mathrm{sdm}$ (in \%) for the combustion experiments, 0.01 percent for the possible effect of organic impurities in the sample, 0.01 percent for the uncertainty in the certified value for benzoic acid, and reasonable estimates of all other sources of error. The uncertainty assigned to $\Delta H f^{\circ}$ was obtained by combining the uncertainty of $\Delta H c^{\circ}$ with estimated uncertainties of 0.01 percent in the values taken for the heats of formation of carbon dioxide and water [3].

A comparison of the results obtained in this investigation with previously reported values for acetanilide and urea is given in table 5. Wadsö [6] calculated the enthalpy of combustion of acetanilide as -1009.5 $\mathrm{kcal} / \mathrm{mol}(-4223.75 \mathrm{~kJ} / \mathrm{mol})$ from measurements of the heat of hydrolysis of acetic anhydride and the heat of reaction of acetic anhydride with aniline. Månsson and Sunner [8] measured the enthalpy of combustion of urea using paraffin oil as an auxiliary and obtained $150.89 \pm 0.02 \mathrm{kcal} / \mathrm{mol}$. Their data agrees well with that obtained by Huffman [9] who used a similar auxiliary material and obtained - 150.99 $\pm 0.04 \mathrm{kcal} / \mathrm{mol}$.

In view of the good agreement between the results it would appear that both of these materials would be quite satisfactory as secondary thermochemical

\begin{tabular}{|c|c|c|c|c|c|c|}
\hline Expt. No. & 390 & 396 & 426 & 427 & 436 & 445 \\
\hline 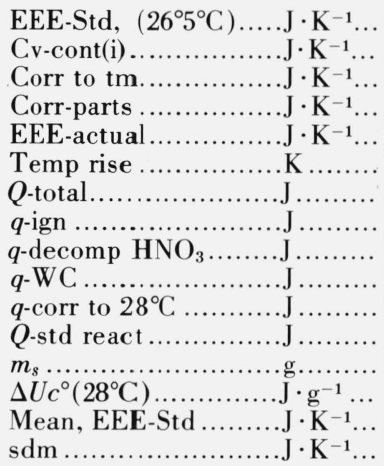 & \begin{tabular}{|c|}
2519.28 \\
4.75 \\
0.13 \\
-0.23 \\
2523.93 \\
3.137830 \\
-7919.66 \\
0.89 \\
0.87 \\
6.30 \\
-0.05 \\
-7911.64 \\
.299566 \\
-26410.36 \\
2519.09 \\
0.15
\end{tabular} & $\begin{array}{c}2519.39 \\
4.72 \\
0.04 \\
-0.23 \\
2523.92 \\
3.059233 \\
-7721.25 \\
1.05 \\
1.01 \\
6.08 \\
-0.02 \\
-7713.13 \\
.292050 \\
-26410.36\end{array}$ & $\begin{array}{c}2518.49 \\
4.86 \\
0.08 \\
0.00 \\
2523.43 \\
3.105295 \\
-7836.00 \\
0.82 \\
0.55 \\
6.19 \\
-0.03 \\
-7828.48 \\
.296417 \\
-26410.36\end{array}$ & $\begin{array}{c}2518.88 \\
4.82 \\
0.14 \\
0.00 \\
2523.84 \\
3.177676 \\
-8019.96 \\
0.79 \\
0.29 \\
6.40 \\
-0.06 \\
-8012.53 \\
.303386 \\
-26410.36\end{array}$ & $\begin{array}{c}2519.50 \\
4.87 \\
0.19 \\
0.00 \\
2524.56 \\
3.203383 \\
-8087.12 \\
0.94 \\
0.12 \\
6.46 \\
-0.07 \\
-8079.68 \\
.305928 \\
-26410.36\end{array}$ & $\begin{array}{c}2518.97 \\
4.75 \\
0.16 \\
0.00 \\
2523.88 \\
3.181825 \\
-8030.54 \\
1.06 \\
2.30 \\
6.38 \\
-0.06 \\
-8020.86 \\
.303701 \\
-26410.36\end{array}$ \\
\hline
\end{tabular}
standards for the calorimetry of nitrogen-containing compounds.

TABLE 1. Results of the benzoic acid calibration experiments 
TABLE 2. Results of the combustion experiments on acetanilide

\begin{tabular}{|c|c|c|c|c|c|c|c|}
\hline Expt. No. & 429 & 437 & 438 & 439 & 440 & 441 & 443 \\
\hline 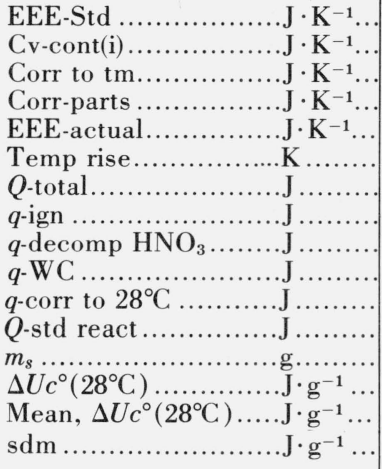 & $\begin{array}{c}2519.09 \\
4.88 \\
0.25 \\
0.00 \\
2524.22 \\
3.274775 \\
-8266.25 \\
0.76 \\
16.01 \\
5.12 \\
-0.10 \\
-8244.46 \\
0.263977 \\
-31231.70 \\
-31230.00 \\
1.72\end{array}$ & $\begin{array}{c}2519.09 \\
15.99 \\
-0.50 \\
0.00 \\
2534.58 \\
2.455891 \\
-6224.65 \\
1.01 \\
9.68 \\
6.98 \\
0.16 \\
-6206.82 \\
0.198784 \\
-31223.87\end{array}$ & $\begin{array}{c}2519.09 \\
15.96 \\
0.22 \\
0.00 \\
2535.27 \\
3.225777 \\
-8178.22 \\
0.91 \\
16.29 \\
9.25 \\
-0.09 \\
-8151.85 \\
0.261033 \\
-31229.14\end{array}$ & $\begin{array}{c}2519.09 \\
15.87 \\
0.19 \\
0.00 \\
2535.15 \\
3.214285 \\
-8148.70 \\
0.84 \\
16.72 \\
9.19 \\
-0.08 \\
-8122.04 \\
0.260104 \\
-31226.08\end{array}$ & $\begin{array}{c}2519.09 \\
15.97 \\
0.22 \\
0.00 \\
2535.28 \\
3.256874 \\
-8257.10 \\
0.91 \\
15.99 \\
9.35 \\
-0.09 \\
-8230.94 \\
0.263557 \\
-31230.18\end{array}$ & $\begin{array}{c}2519.09 \\
15.95 \\
0.19 \\
0.00 \\
2535.24 \\
3.223884 \\
-8173.33 \\
1.06 \\
16.51 \\
9.24 \\
-0.08 \\
-8146.60 \\
0.260851 \\
-31230.81\end{array}$ & $\begin{array}{c}2519.09 \\
15.94 \\
0.17 \\
0.00 \\
2535.20 \\
3.232475 \\
-8194.96 \\
0.81 \\
16.30 \\
9.24 \\
-0.08 \\
-8168.69 \\
0.261497 \\
-31238.19\end{array}$ \\
\hline
\end{tabular}

TABLE 3. Results of the combustion experiments on urea

\begin{tabular}{|c|c|c|c|c|c|c|c|}
\hline Expt. No. & 430 & 431 & 432 & 433 & 434 & 435 & 444 \\
\hline 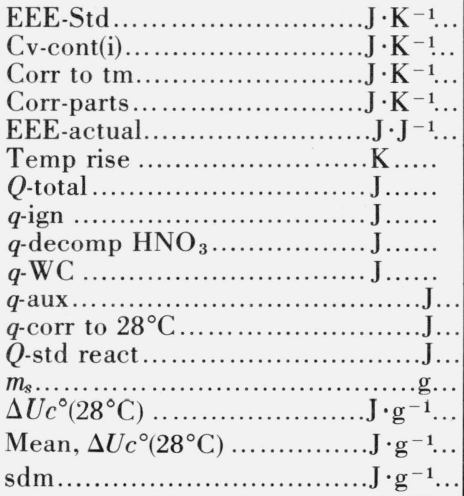 & $\begin{array}{c}2519.09 \\
16.87 \\
0.29 \\
0.00 \\
2536.25 \\
3.329777 \\
-8445.15 \\
0.79 \\
27.21 \\
11.96 \\
447.32 \\
-0.31 \\
-7958.17 \\
0.755195 \\
-10537.90 \\
-10536.75 \\
0.30\end{array}$ & $\begin{array}{c}2519.09 \\
16.81 \\
0.08 \\
0.00 \\
2535.98 \\
3.093843 \\
-7845.92 \\
0.86 \\
25.10 \\
11.08 \\
411.34 \\
-0.08 \\
-7397.61 \\
0.702119 \\
-10536.12\end{array}$ & $\begin{array}{c}2519.09 \\
16.79 \\
0.04 \\
0.00 \\
2535.92 \\
3.044748 \\
-7721.24 \\
0.92 \\
25.20 \\
10.87 \\
295.78 \\
-0.04 \\
-7388.51 \\
0.701249 \\
-10536.23\end{array}$ & $\begin{array}{c}2519.09 \\
16.80 \\
0.05 \\
0.00 \\
2535.94 \\
3.068810 \\
-7782.32 \\
0.81 \\
25.29 \\
10.97 \\
382.26 \\
-0.06 \\
-7363.04 \\
0.698866 \\
-10535.71\end{array}$ & $\begin{array}{c}2519.09 \\
16.80 \\
0.09 \\
0.00 \\
2535.98 \\
3.110405 \\
-7887.93 \\
0.89 \\
26.25 \\
11.11 \\
434.61 \\
-0.09 \\
-7415.16 \\
0.703709 \\
-10537.26\end{array}$ & $\begin{array}{c}2519.09 \\
16.83 \\
0.15 \\
0.00 \\
2536.07 \\
3.166079 \\
-8029.39 \\
0.81 \\
24.80 \\
11.37 \\
441.32 \\
-0.15 \\
-7551.23 \\
0.716609 \\
-10537.45\end{array}$ & $\begin{array}{c}2519.09 \\
16.79 \\
0.03 \\
0.00 \\
2535.91 \\
3.036571 \\
-7700.47 \\
0.96 \\
25.01 \\
10.85 \\
327.06 \\
-0.03 \\
-7336.63 \\
0.696301 \\
-10536.58\end{array}$ \\
\hline
\end{tabular}


TABLE 4

\begin{tabular}{l|c|c}
\hline \hline & Acetanilide & Urea \\
\cline { 2 - 3 }$\Delta U c^{\circ}\left(28^{\circ} \mathrm{C}\right)$ & $-31230.00 \pm 6.87 \mathrm{~J} / \mathrm{g}$ & $-10536.75 \pm 2.74 \mathrm{~J} / \mathrm{g}$ \\
$\Delta H c^{\circ}\left(28^{\circ} \mathrm{C}\right)$ & $-4224.34 \pm 0.93 \mathrm{~kJ} / \mathrm{mol}$ & $-631.54 \pm 0.16 \mathrm{~kJ} / \mathrm{mol}$ \\
$\Delta H c^{\circ}\left(25^{\circ} \mathrm{C}\right)$ & $-4224.88 \pm 0.93 \mathrm{~kJ} / \mathrm{mol}$ & $-631.78 \pm 0.16 \mathrm{~kJ} / \mathrm{mol}$ \\
$\Delta H f^{\circ}\left(25^{\circ} \mathrm{C}\right)$ & $-209.44 \pm 1.00 \mathrm{~kJ} / \mathrm{mol}$ & $-333.39 \pm 0.17 \mathrm{~kJ} / \mathrm{mol}$ \\
\hline
\end{tabular}

TABLE 5. Comparison with previously reported values

\begin{tabular}{|c|c|c|}
\hline & $\begin{array}{c}\text { Acetanilide } \\
\Delta H c^{\circ}\left(25^{\circ} \mathrm{C}\right), \mathrm{kJ} / \mathrm{mol}\end{array}$ & $\begin{array}{c}\text { Urea } \\
\Delta H c^{\circ}\left(25^{\circ} \mathrm{C}\right), \mathrm{kJ} / \mathrm{mol}\end{array}$ \\
\hline Wadsö.................. & \multirow[t]{3}{*}{$-4223.75[7]$} & \\
\hline Månsson and Sunner... & & $-631.33 \pm 0.10[8]$ \\
\hline Huffman...$\ldots \ldots \ldots \ldots$ & & $-631.75 \pm 0.18[9]$ \\
\hline This investigation ..... & $-4224.88 \pm 0.93$ & $-631.78 \pm 0.17$ \\
\hline
\end{tabular}

This work was supported, in part, by the Office of Standard Reference Materials of the National Bureau of Standards.

\section{References}

[1] Prosen, E. J., and Johnson, W. H., in preparation.

[2] Armstrong, G. T., and Johnson, W. H., NBSIR 73-158(July 1973).

[3] Wagman, D. D., Evans, W. H., Parker, V. B., Halow, I., Bailey, S. M., and Schumm, R. H., Selected values of chemical thermodynamic properties, Nat. Bur. Stand. (U.S.), Tech. Note 270-3, 267 pages (Jan. 1968).

[4] Commission on Atomic Weights, Pure and Applied Chem. 30, $637(1972)$

[5] Washburn, E. W., BS J. Research 10, 525 (1933).

[6] Hubbard, W. N., Scott, D. W., and Waddington, G., J. Phys. Chem. 58, 152 (1954).

[7] Wadsö, I., Acta Chem. Scand. 16, 471 (1962).

[8] Månsson, M., and Sunner, S., Acta Chem. Scand. 17, 723 (1963).

[9] Huffman, H. M., J. Am. Chem. Soc. 62, 1009 (1940).

(Paper 79A3-853) 